\title{
Implementasi Pemilihan Motor Bekas Menggunakan Metode AHP-TOPSIS
}

\author{
Alviani Setya Yuniantika ${ }^{a}$, Wiwien Hadikurniawati ${ }^{b}$ \\ Fakultas Teknologi Informasi, Universitas Stikubank, Jl. Tri LombaJuang No 1, Semarang, Jawa Tengah \\ Fakultas Teknologi Informasi, Universitas Stikubank, Jl. Tri LombaJuang No 1, Semarang, Jawa Tengah
}

\section{INFORMASI ARTIKEL}

Sejarah Artikel:

Diterima Redaksi: 21 April 2021

Revisi Akhir: 22 Mei 2021

Diterbitkan Online: 30 Mei 2021

\section{KATA KUNCI}

SPK;

Motor Bekas;

AHP; TOPSIS

\section{KORESPONDENSI}

E-mail: alviani.seyu@gmail.com

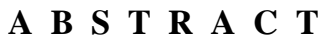

A motorcycle is a means of transportation device that uses an engine and two wheels. Indirectly, human needs are resolved by using motorcycle. Limited economic conditions are the reason people buy second-hand motorcycle. The number of models and various conditions of second-hand motorcycle make it difficult for people to choose the one to be purchased. This study aims to recommend alternative solutions as a consideration in choosing a second-hand motorcycle. The solution to this problem uses the AHP and TOPSIS methods. The AHP method was chosen because it produces weighted criteria. TOPSIS was chosen because for ranking it is expected to provide the best second-hand motorcycle recommendation solutions to customer.

\section{PENDAHULUAN}

Kendaraan motor merupakan salah satu alat transportasi dalam penggunaan yang banyak dibutuhkan di masyarakat .Dalam keadaan macet motor dapat memberikan mobilitas yang baik.Sepeda motor merupakan salah satu kebutuhan primer, untuk masyarakat ekonomi kelas menengah [1]. Keterbatasan ekonomi sebagian masyarakat untuk membeli motor baru mengalami kendala.Sehingga cara alternatif dengan memilih membeli motor bekas. Motor bekas adalah motor yang dibeli seseorang dalam keadaan baru dan sudah dipake,kemudian dijualkan kepada orang lain.

PT. Prima Motor adalah dealer motor bekas terpercaya dalam memasarkan kendaraan dengan merk Honda. Dealer Prima Motor terletak di daerah Kuwu,Grobogan Jawa Tengah. Honda adalah adalah jenis merk motor yang paling diminati oleh kalangan masyarakat Indonesia.
Dalam pemilihan mengalami kesulitan dalam membantu konsumen menentukan pilihan kendaraan yang akan dibeli. Hal ini disebabkan begitu banyaknya tipe motor dalam satu merk.

Konsumen dalam memilih kendaraan yang tepat sesuai kebutuhan dan dana yang dimiliki membutuhkan suatu kajian yang baik,untuk mempertimbangkan kriteria dan spesifikasi untuk memilih motor yang akan dibeli [2].

Untuk mengatasi permasalahan tersebut,sistem pendukung keputusan yang dikembangkan sebagai sistem pendukung dalam menyelesaikan permasalahan dan menghasilkan suatu keputusan. Penelitian ini menerapkan metode Analytical Hierarchy Process (AHP) dan Technique for Order Preference by Similarity to Ideal Solution (TOPSIS). Metode Analytical Hierarchy Process (AHP) digunakan untuk penentuan bobot kriteria,sedangkan untuk metode Technique for Order Preference Similarity to Ideal Solutio $n$ (TOPSIS) digunakan untuk penentuan peringkatan. Sehinga diharapkan 
dapat memberi solusi rekomendasi motor bekas terbaik untuk konsumen yang akan membeli.

\section{TINJAUAN PUSTAKA}

Adinta, melakukan penelitian membahas mengenai bagaimana metode AHP (Analytic Hierarchy Process) diaplikasikan dalam pemilihan sepeda motor honda. Metode AHP digunakan untuk mengambil keputusan [3]. Tati menyatakan penelitian mengenai sistem pendukung keputusan penerimaan terhadap asisten laboratorium komputer dengan menerapkan metode AHP- TOPSIS. Dalam penelitian tersebut,dapat menunjang proses pembelajaran dalam pemilihan asisten laboratorium komputer[4].

Penelitian selanjutnya,dilakukan oleh Halim,Ricky menyatakan metode TOPSIS menunjang dalam pemilihan siswa teladan menghasilkan pertimbangan nilai alternative hingga terbesar untuk perangkingan siswa terbaik [5]. Penelitian dilalukan oleh Gede Surya, Putu membahas mengenai penerapan metode AHP-TOPSIS untuk menentukan penempatan ATM dengan menghasilkan bobot kriteria dan nilai prefensi [6].

\section{METODOLOGI}

Sistem pendukung keputusan motor bekas menggunakan metode kombinasi AHP dan TOPSIS. Metode AHP digunakan untuk penentuan bobot kriteria,sedangkan metode TOPSIS digunakan untuk menghasilkan perangkingan.Proses implementasi pada AHP memiliki 4 (empat) yaitu menentukan kriteria, kriteria perbandingan berpasangan,pembagian nilai matriks, dan nilai bobot prioritas.

Pada proses TOPSIS memiliki 6 tahapan proses yaitu menentukan bobots setiap alternative, menghitung matriks normalisasi bobot,normalisasi- normlaisasi matrik keputusan,matriks solusi ideal positif dan negative tiap kriteria,menghitung jarak ideal negative dan ideal positif tiap alternative,dan terakhir menghitung hasil preferensi untuk menentukan perangkingan. Alur metode ditunjukkan dengan diagram blok sebagai gambaran proses.

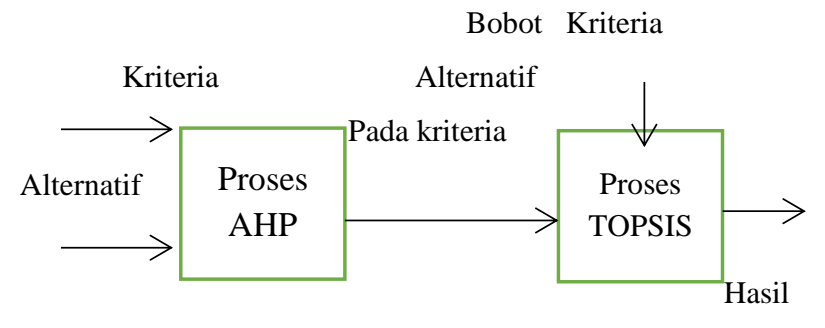

Gambar 1. Diagram Blok

\section{HASIL DAN PEMBAHASAN}

\subsection{Tabel}

Proses menentukan kriteria pemilihan motor bekas digunakan sebagai perbandingan. Diperoleh 5 kriteria yang digunakan yaitu tahun,harga,kelengkapan surat,keaslian sparepart,desain.

Tabel 1. Data Kriteria

\begin{tabular}{ll}
\hline Kriteria & Keterangan \\
\hline C1 & Tahun \\
C2 & Harga \\
C3 & Kelengkapan Surat \\
C4 & Keaslian Sparepart \\
C5 & Desain \\
\hline
\end{tabular}

Proses menentukanalternatif pada dealer Prima Motor khusus Honda denganmengambil 5 alternatif

Tabel 2. Data Alternatif

\begin{tabular}{ll}
\hline Alternatif & Keterangan \\
\hline A1 & Vario 125 \\
A2 & Vario 150 \\
A3 & Scoopy \\
A4 & Beat \\
A5 & CRF 150 \\
\hline
\end{tabular}

\section{Perhitungan AHP}

Pada proses ini untuk menentukan bobot setiap kriteria. [proses perhitungan pada metode AHP memiliki tahapan tahapan sebagai berikut :

Tabel 3. Matriks Perbandingan Berpasangan

\begin{tabular}{cccccc}
\hline & C1 & C2 & C3 & C4 & C5 \\
\hline C1 & 1 & 2 & 3 & 5 & 5 \\
C2 & 0.5 & 1 & 3 & 3 & 5 \\
C3 & 0,33 & 0,33 & 1 & 3 & 5 \\
C4 & 0,2 & 0,33 & 0,33 & 1 & 3
\end{tabular}


$\begin{array}{llllll}\text { C5 } & 0,2 & 0,2 & 0,2 & 0,3 & 1\end{array}$

$\begin{array}{lllll}\text { Jumlah } & 2,23 & 3,86 & 7,53 & 12,3\end{array} 19$

Pada table 4 merupakan proses perhitungan bobot prioritas dengan membagi nilai matriks perbandingan dengan jumlah kolom,berikutnya menjumlahkan perbaris

Tabel 4.Pembagian Nilai Matriks Perbandingan

\begin{tabular}{cccccc}
\hline & C1 & C2 & C3 & C4 & C5 \\
\hline C1 & $1 / 2,23$ & $2 / 3,86$ & $3 / 7,53$ & $5 / 12,3$ & $5 / 19$ \\
C2 & $0.5 / 2,23$ & $1 / 3,86$ & $3 / 7,53$ & $3 / 12,3$ & $5 / 19$ \\
C3 & $0,33 / 2,23$ & $0,33 / 3,86$ & $1 / 7,53$ & $3 / 12,3$ & $5 / 19$ \\
C4 & $0,2 / 2,23$ & $0,33 / 3,86$ & $0,33 / 7,53$ & $1 / 0,3$ & $3 / 19$ \\
C5 & $0,2 / 2,23$ & $0,2 / 3,86$ & $0,2 / 7,53$ & $0,3 / 12,3$ & $1 / 19$
\end{tabular}

Dari kolom C1 jumlah dari kolom $\mathrm{C} 1$ adalah 2,23,angka 1 di kolom $\mathrm{C} 1$ baris $\mathrm{C} 1$ dibagi dengan 2,23 menghasilkan angka 0,44843,angka 0,5 di kolom C1 baris C2 dibagi dengan 2,23 menghasilkan angka 0,22422. Tahapan berikutnya dengan perhitungan yang sama.

Tabel 5 menunjukkan hasil pembagian dari semua baris dan kolom dengan jumlah kolom masing-masing kriteria

Tabel 5. Bobot Prioritas

\begin{tabular}{cccccc}
\hline & $\mathbf{C 1}$ & $\mathbf{C 2}$ & $\mathbf{C 3}$ & $\mathbf{C 4}$ & $\mathbf{C 5}$ \\
\hline $\mathbf{C}$ & 0,4484 & 0,51813 & 0,39840 & 0,40650 & 0,26315 \\
$\mathbf{1}$ & 3 & 1 & 6 & 4 & 8 \\
$\mathbf{C}$ & 0,2242 & 0,25906 & 0,39840 & 0,24390 & 0,26315 \\
$\mathbf{2}$ & 2 & 7 & 6 & 2 & 8 \\
$\mathbf{C}$ & 0,1479 & 0,08549 & 0,13280 & 0,24390 & 0,26315 \\
$\mathbf{3}$ & 8 & 2 & 2 & 2 & 8 \\
$\mathbf{C}$ & 0,0896 & 0,08549 & 0,04382 & 0,08130 & 0,15789 \\
$\mathbf{4}$ & 9 & 2 & 5 & 1 & 5 \\
$\mathbf{C}$ & 0,0896 & 0,05181 & 0,02656 & 0,02439 & 0,05263 \\
$\mathbf{5}$ & 9 & 3 & & & 2
\end{tabular}

\section{Tahapan TOPSIS}

1. Pembobotan alternatif

Tolok ukur kecocokan setiap alternatif dinilai dengan tabel ini.

Tabel 6. Data Alternatif

$\begin{array}{lllll}\text { A1 } & \text { A2 } & \text { A3 } & \text { A4 } & \text { A5 }\end{array}$

$\begin{array}{llllll}\text { A1 } & 6 & 5 & 6 & 5 & 4 \\ \text { A2 } & 5 & 6 & 6 & 4 & 3 \\ \text { A3 } & 4 & 5 & 5 & 5 & 4 \\ \text { A4 } & 3 & 5 & 5 & 3 & 5 \\ \text { A5 } & 5 & 5 & 5 & 6 & 4\end{array}$

2. Membuat matriks perbandingan berpasangan yang ternormalisasi

Proses perhitungan normalisasi setiap alternatif dihitung menggunakan rumus $r_{i j}=\frac{X_{i j}}{\sqrt{\sum_{i=1}^{m} x_{i j}^{2}}}$ sehingga di dapatkan hasil sebagai berikut :

Keterangan :

$r_{i j}=$ Elemen matriks normalisasi $[\mathrm{i}][\mathrm{j}]$

$X_{i j}=$ Elemen matriks keputusan $\mathrm{X}$

Tabel 7. Pembobotan Alternatif

\begin{tabular}{cccccc}
\hline & C1 & C2 & C3 & C4 & C5 \\
\hline A1 & 75,1667 & 111,2 & 111,16 & 86,2 & 66,25 \\
A2 & 75.13889 & 111,24 & 111,1667 & 86,16 & 66,1875 \\
A3 & 75,11111 & 111,2 & 111,139 & 86,2 & 66,25 \\
A4 & 75,08333 & 111,2 & 111,139 & 86,12 & 66,3125 \\
A5 & 75,13889 & 111,2 & 111,1389 & 86,24 & 66,25
\end{tabular}

3. Menentukan sebuah matriks normalisasi keputusan terbobot

Tabel 8. Normalisasi Data

\begin{tabular}{cccccc}
\hline & $\mathbf{C 1}$ & $\mathbf{C 2}$ & $\mathbf{C 3}$ & $\mathbf{C 4}$ & $\mathbf{C 5}$ \\
\hline $\mathbf{A}$ & 152,936 & 154,428 & 97,0859 & 39,4967 & 16,2366 \\
$\mathbf{1}$ & 6 & 9 & 4 & 2 & 7 \\
$\mathbf{A}$ & 152,880 & 154,484 & 97,0859 & 39,4783 & 16,2213 \\
$\mathbf{2}$ & 1 & 5 & 4 & 9 & 5 \\
$\mathbf{A}$ & 152,823 & 154,428 & 97,0616 & 39,4967 & 16,2366 \\
$\mathbf{3}$ & 6 & 9 & 8 & 2 & 7 \\
$\mathbf{A}$ & 152,767 & 154,428 & 97,0616 & 39,4600 & 16,2519 \\
$\mathbf{4}$ & 1 & 9 & 8 & 6 & 9 \\
$\mathbf{A}$ & 152,880 & 154,428 & 97,0616 & 39,5150 & 16,2366 \\
$\mathbf{5}$ & 1 & 9 & 8 & 5 & 7
\end{tabular}

Pada tabel ini merupakan hasil normalisasi perbandingan berpasangan. Proses normalisasi dari alternative dengan kriteria seperti :

$$
\begin{aligned}
& R_{6}=6 / 6^{2}+5^{2}+4^{2}+3^{2}+5^{2}=75,16667 \\
& R_{7}=5 / 6^{2}+5^{2}+5^{2}+4^{2}+3^{2}+5^{2}=75,13889
\end{aligned}
$$

Implementasi Pemilihan Motor Bekas 
Begitupun dengan alternatif lain menggunakan kriteria yg ditetapkan.

4. Menentukan solusi ideal positif dan solusi ideal negatif.Tahapan proses menentukan solusi ideal positif didapatkan dari nilai terbesar dalam hasil normalisasi terbobot pada setiap kriteria dan ideal negatif didapatkan dari nilai terkecil

Tabel 9.Solusi Ideal Positif dan Negatif

\begin{tabular}{lccccc}
\hline & C1 & C2 & C3 & C4 & C5 \\
\hline Ideal( & 152,93 & 154,48 & 97,085 & 39,515 & 16,251 \\
$+)$ & 66 & 45 & 94 & 05 & 99 \\
Ideal(- & 152,76 & 154,42 & 97,061 & 39,460 & 16,221 \\
) & 71 & 89 & 68 & 06 & 35
\end{tabular}

1. Menentukan jarak nilai setiap alternatif dengan solusi ideal positif dan negatif

Tahapan proses menentukan jarak setiap alternatif pada solusi ideal positif dan negatif

Solusi ideal (+) $D_{i}^{+}=\sqrt{\sum_{j=1}^{n}\left(y_{i j}-y_{i}^{+}\right)^{2}}$ \& Solusi ideal (-) $D_{i}^{-}=\sqrt{\sum_{j=1}^{n}\left(y_{i j}-y_{i}^{-}\right)^{2}}$

Keterangan :

$D_{i}^{+}=$Jarak alternatif ke-i dengan solusi ideal positif

$y_{i j}=$ Elemen matriks, normalisasi bobot [i][j]

$y_{i}^{+}=$Elemen solusi ideal positif[i]

$D_{i}^{-}=$Jarak alternatif ke-i solusi ideal negatif

$y_{i}^{-}=$Elemen solusi ideal negatif[i]

$y_{i j}=$ Elemen matriks normalisasi bobot[i][j]

sehingga didapatkan hasil seperti berikut.

Tabel Jarak Solusi Ideal Positif dan Solusi Ideal Negatif

Tabel 10 Solusi Ideal Positif dan Solusi Ideal Negatif

\begin{tabular}{llll}
\hline Vario 125 & 0,060494 & Motor 1 & 0,175796 \\
Vario 150 & 0,07399 & Motor 2 & 0,129547 \\
Scoopy & 0,130462 & Motor 3 & 0,069059 \\
Beat & 0,188261 & Motor 4 & 0,030638 \\
CRF 150 & 0,084285 & Motor 5 & 0,126601
\end{tabular}

Cara perhitunganjarakalternatifsolusi ideal positifsepertiberikut :

$\mathrm{D} 1=\sqrt{ }(152,9366-152,9366) 2+(154,4845-154,4289) 2+$ $(97,08594-97,08594) 2+(39,51505-39,47839) 2+(16,25199-$ $16,22135) 2=0,060494$

$\mathrm{D} 2=\sqrt{ }(152,9366-152,9366) 2+(154,4845-154,4845) 2+$ $(97,08594-97,08594) 2+(39,51505-39,51505) 2+(16,25199-$ $16,25199) 2=0,07399$

Cara perhitunganjarakalternatifsolusi ideal negative sepertiberikut :

$\mathrm{D} 1=\sqrt{(152,9366-152,7671) 2+(154,4289-154,4289) 2+}$ $(97,08594-97,06168) 2+(39,49672-39,46006) 2+(16,23667$ $-16,22135) 2=0,175796$

$\mathrm{D} 2=\sqrt{(} 152,8801-152,7671) 2+(154,4845-154,4289) 2+$ $(97,08594-97,08594) 2+(39,51505-39,46006) 2+(16,25199-$ $16,22135) 2=0,129547$

\section{Menentukan Nilai Preferensi}

Tahapan proses menentukan nilai preferensi dihitung dengan menggunakanr umus $V_{i}=\frac{D_{i}^{-}}{D_{i}^{-}+D_{i}^{+}}$

Keterangan :

$$
\begin{aligned}
& \mathrm{V}_{\mathrm{i}}=\text { Kedekatanalternatifterhadapsolusi ideal } \\
& \quad D_{i}^{-}=\text {Jarak alternatifke }- \text { idengansolusi ideal negatif } \\
& D_{i}^{+}=\text {Jarak alternatifke- I dengan solusi } \\
& \text { ideal positif }
\end{aligned}
$$

Tabel 11.Hasil Nilai Preferensi

\begin{tabular}{lcc}
\hline Alternatif & $\begin{array}{c}\text { Nilai } \\
\text { Preferensi }\end{array}$ & Alternatif \\
\hline Vario 125 & 0,743984 & 1 \\
Vario 150 & 0,636481 & 2 \\
Scoopy & 0,346124 & 4 \\
Beat & 0,139964 & 5 \\
CRF 150 & 0,600329 & 3
\end{tabular}




\subsection{Implementasi}

Berdasarkan rancangan dan perhitungan, diimplimentasikan sebagai beriku tini.

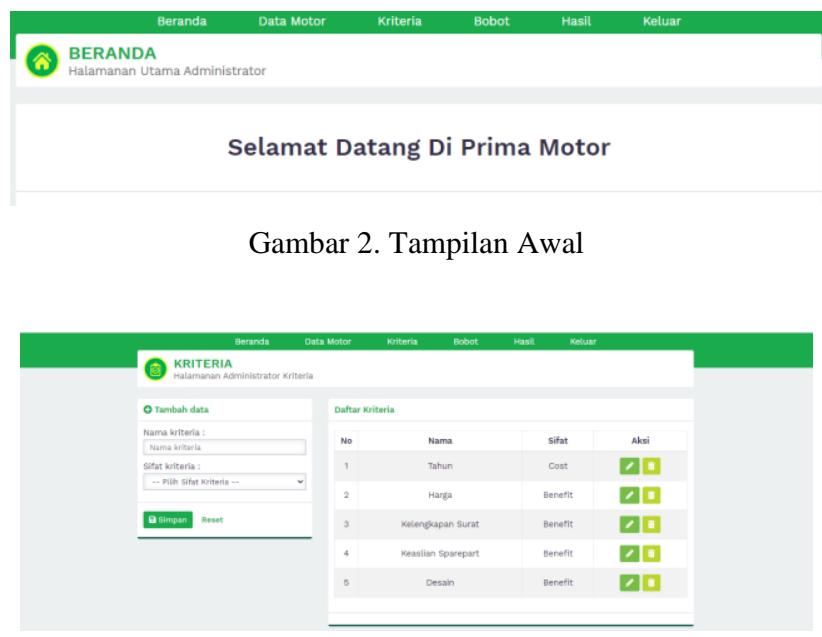

Gambar 3.Tampilan Kriteria

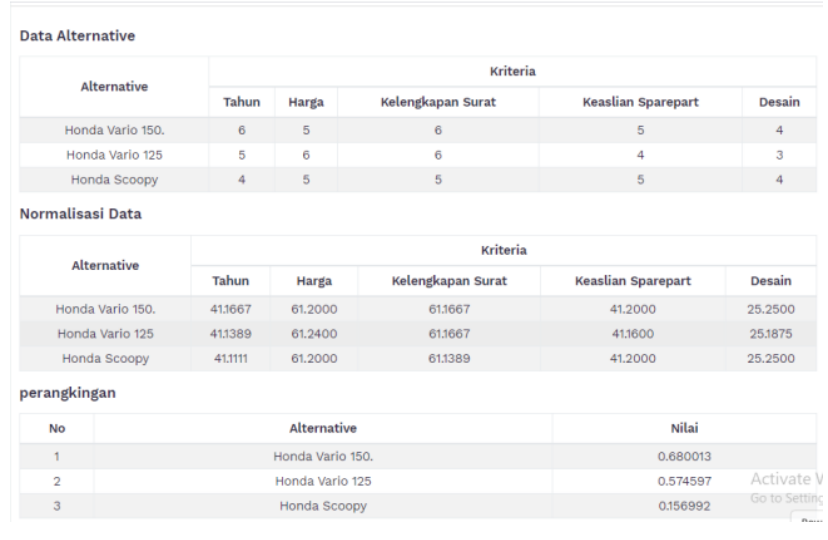

Gambar.4 Implementasi Sistem

\section{KESIMPULAN DAN SARAN}

Berdasarkan hasil penelitian dalam menentukan motorbekas terbaik dengan metode AHP-TOPSIS.AHP digunakan untuk bobot kriteria, sedangkanTOPSIS digunakan untuk perangkingan.Dalam penelitian penelitian ini terdiri 5 kriteria yaitu :

Tahun (C1), Harga (C2), Kelengkapansurat (C3), Keasliansparepart (C4), Desain(C5), dan terdiri 5 alternatifyaituVario 125 (A1), Vario 150 (A2), Scoopy (A3), Beat (A4), CRF 150 (A5).

\section{DAFTAR PUSTAKA}

[1] Arifin, N. A. (2020). Sistem Pendukung Keputusan Pemilihan Sepeda Motor Bekas dengan Metode AHP dan SAW (StudiKasus: Sahabat Motor). STRING (Satuan
Tulisan Riset Dan InovasiTeknologi), 5(2), 160. https://doi.org/10.30998/string.v5i2.7739

[2] Yuliarifin, A. (2019). Sistem Pendukung Keputusan PembelianSepeda Motor Honda Pada Dealer KembangJawa Motor Trenggalek Dengan Metode Analythical Hierarchy Process ( Ahp ) Berbasis Web. 3(1), $17-23$.

[3] Rizaldi, R. (2017). Penentuan Operator Kartu Seluler Terbaik Menggunakan Metode Ahp (Analitycal Hierarchy Process). Jurnal Teknologi Informasi, 1(1), 61. https://doi.org/10.36294/jurti.v1i1.44

[4] Ayu, T. I., Ariyanto, R., \&Syaifudin, Y. W. (2017). Sistem Pendukung Keputusan Kenaikan Jabatan Dengan Metode Ahp-Topsis (StudiKasus: Pt. Makmur Citra Abadi). JurnalInformatikaPolinema, $3(3)$ 9. https://doi.org/10.33795/jip.v3i3.27.

[5] Agung, H., \& Ricky. (2016). Teladan Menggunakan Metode Topsis. VIII(2), 112-126.

[6] Mahendra, G. S. (2020). MetodeAhp-Topsis Pada Sistem Pendukung Keputusan Penentuan Penempatan Atm. JST (JurnalSains Dan Teknologi), 9(2). https://doi.org/10.23887/jst-undiksha.v9i2.245

[7] Ayu, T. I., Ariyanto, R., \&Syaifudin, Y. W. (2017). Sistem Pendukung Keputusan Kenaikan Jabatan Dengan Metode Ahp-Topsis (Studi Kasus: Pt. Makmur Citra Abadi). Jurnal Informatika Polinema, 3(3), 9. https://doi.org/10.33795/jip.v3i3.27.

[8] D. Walangare, R. Delima, and Restyandito, "Sistem Prediksi Pertandingan Sepak Bola dengan Metode Analytical Hierarchy Process (AHP)," J. Inform., vol. 8, no. 2, pp. 181-188, 2012, doi: 10.21460/inf.2012.82.127

\section{BIODATA PENULIS}

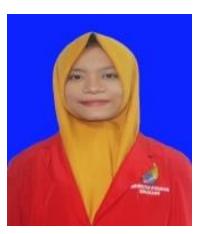

\section{Alviani Setya Yuniantika}

Mahasiswa dari Universitas Stikubank Semarang Program Studi Teknik Informatika Email : alviani.seyu@gmail.com

\section{Wiwien Hadikurniawati}

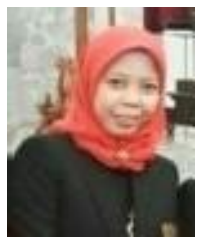
Dosen Fakultas Teknologi Informasi berlatar belakang pendidikan S2 Magister Sistem Informasi Universitas Diponegoro Semarang 